\title{
X-ray characterization of oriented $\beta$-tantalum films
}

\author{
Sandeep Kohli ${ }^{\mathrm{a}, *}$, Patrick R. McCurdy ${ }^{\mathrm{a}}$, Christopher D. Rithner ${ }^{\mathrm{a}}$, Peter K. Dorhout ${ }^{\mathrm{a}}$, \\ Ann M. Dummer ${ }^{\mathrm{b}}$, Fernando Brizuela ${ }^{\mathrm{b}}$, Carmen S. Menoni ${ }^{\mathrm{b}}$ \\ a Department of Chemistry, Colorado State University, Fort Collins CO-80523, United States \\ ${ }^{\mathrm{b}}$ NSF Extreme Ultraviolet Science and Technology Center and Department of Electrical Engineering, \\ Colorado State University, Fort Collins CO-80523, United States
}

Available online 30 October 2004

\begin{abstract}
Tantalum (Ta) metal films $(10-70 \mathrm{~nm})$ were deposited on a $\mathrm{Si}(100)$ substrate with a $500 \mathrm{~nm}$ silicon dioxide $\left(\mathrm{SiO}_{2}\right)$ interlayer by ion-beamassisted sputtering. The as-deposited films have been characterized by X-ray diffraction (XRD) and X-ray reflectivity (XRR) techniques. XRD measurements showed the presence of films of the tetragonal phase of tantalum ( $\beta-T a)$ oriented along the (001) plane. XRR measurements indicated the presence of graded Ta films, with a thin interface layer between the $500 \mathrm{~nm} \mathrm{SiO}_{2}$ layer and the Ta films. The thickness and density of this interface layer was estimated to be $1.9 \pm 0.2 \mathrm{~nm}$ and $10.5 \pm 0.5 \mathrm{~g} / \mathrm{cm}^{3}$, respectively. X-ray photoelectron spectroscopy (XPS) was used to probe the chemical composition of this interface layer. XPS investigative studies indicated that the interface was likely composed of tantalum silicide $\left(\mathrm{TaSi}_{2}\right)$ and tantalum silicate $\left(\mathrm{TaSiO}_{x}\right)$. However, the $\mathrm{TaSiO}_{x}$ layer was reduced during $\mathrm{Ar}$ ion sputter depth profile analysis.
\end{abstract}

(C) 2004 Elsevier B.V. All rights reserved.

Keywords: X-ray diffraction; X-ray reflectivity; X-ray photoelectron spectroscopy; Tantalum; Sputtering

\section{Introduction}

Currently, copper metallization is being extensively utilized as an interconnect for Ultra Large Scale Integration (ULSI) applications. However, an underlying layer is necessary for the adhesion of $\mathrm{Cu}$ to dielectrics, and more importantly, as a diffusion barrier against the migration of copper ions through the dielectric layer [1]. Tantalum (Ta) metal and $\mathrm{Ta}-\mathrm{N}$ intermetallics are being used for $\mathrm{Cu}$ adhesion and as diffusion barriers. The texture and grain structure of $\mathrm{Cu}$ films has been shown to affect the electromigration lifetime of $\mathrm{Cu}$ interconnects [2] with that of (111) oriented $\mathrm{Cu}$ about four times longer than that of (200) oriented $\mathrm{Cu}$ [2]. It has been shown that the growth of $\mathrm{Cu}(111)$ is preferred on $\beta$ Ta films oriented along (002) crystallographic planes [3].

Despite these and other studies devoted to $\beta-\mathrm{Ta}$ [4-8], the growth mechanism of oriented $\beta-\mathrm{Ta}$ is not clear. There is

\footnotetext{
* Corresponding author. Tel.: +1 970491 4076; fax: +1 9704911801.
}

E-mail address: skohli@lamar.colostate.edu (S. Kohli). sufficient lack of information on the related properties of oriented $\beta-\mathrm{Ta} /$ silicon dioxide $\left(\mathrm{SiO}_{2}\right)$ and the $\beta-\mathrm{Ta} / \mathrm{Si}$ interface. In the present paper, the dual ion beam sputtering deposition technique was used to deposit 10-70 nm tantalum films on $\mathrm{Si}$ substrates with a pre-deposited 500 $\mathrm{nm} \mathrm{SiO}_{2}$ layer. X-ray diffraction (XRD), X-ray reflectivity (XRR) and X-ray photoelectron spectroscopy (XPS) techniques were used to investigate the structural and chemical properties of tantalum metal thin films and their interface with the underlying $\mathrm{SiO}_{2}$ film.

\section{Experimental procedure}

Films of Ta metal and $\mathrm{SiO}_{2}$ were deposited using a dual ion beam sputtering deposition technique (Spector IBD system, Veeco) [9]. Ta films (10, 30 and $70 \mathrm{~nm})$ were deposited on the $\mathrm{Si}(100)$ substrate pre-coated with a $500 \mathrm{~nm}$ $\mathrm{SiO}_{2}$ layer interlayer. A deposition rate of $0.24 \mathrm{~nm} / \mathrm{s}$ was achieved using deposition source ion energy of $1250 \mathrm{eV}$. Base pressure was less than $10^{-3} \mathrm{~Pa}$ and chamber temper- 
ature was $\sim 115{ }^{\circ} \mathrm{C}$. Argon flow rate was held at $36 \mathrm{sccm}$. $\mathrm{XRD}$ and XRR measurements were performed using a Bruker D-8 Discover instrument using $\mathrm{Cu} \mathrm{K} \mathrm{K}_{\alpha}$ radiation $(E=8041.3 \mathrm{eV})$. XPS measurements were performed using a Physical Electronics ESCA 5800 system. Monochromatic $\mathrm{Al} \mathrm{K}_{\alpha}(E=1486.6 \mathrm{eV})$, was employed as an X-ray source. The high-resolution XPS scans for chemical state identification were carried out using pass energy of $23.5 \mathrm{eV}$ and step size of $0.1 \mathrm{eV}$. More details for experimental procedure have been published elsewhere $[10,11]$.

\section{Results}

The XRD patterns (Fig. 1) of as-deposited 10-70 nm tantalum films indicated the presence of the tetragonal $\mathrm{Ta}$ phase $(\beta-\mathrm{Ta})[12]$ with preferred orientation along $(001)$. The absence of diffraction peaks other than Ta (002), (004) and (006) indicated the presence of strong texture in these as-deposited films. The Si (400) peak overlapped with (004) reflection from $\beta$-Ta. The XRD data from the $10 \mathrm{~nm}$ Ta film had a low signal to the noise ratio; however, the Ta (002) peak could be clearly seen. While a peak for tetragonal $\mathrm{TaO}_{2}$ [13] oriented along (200) could be
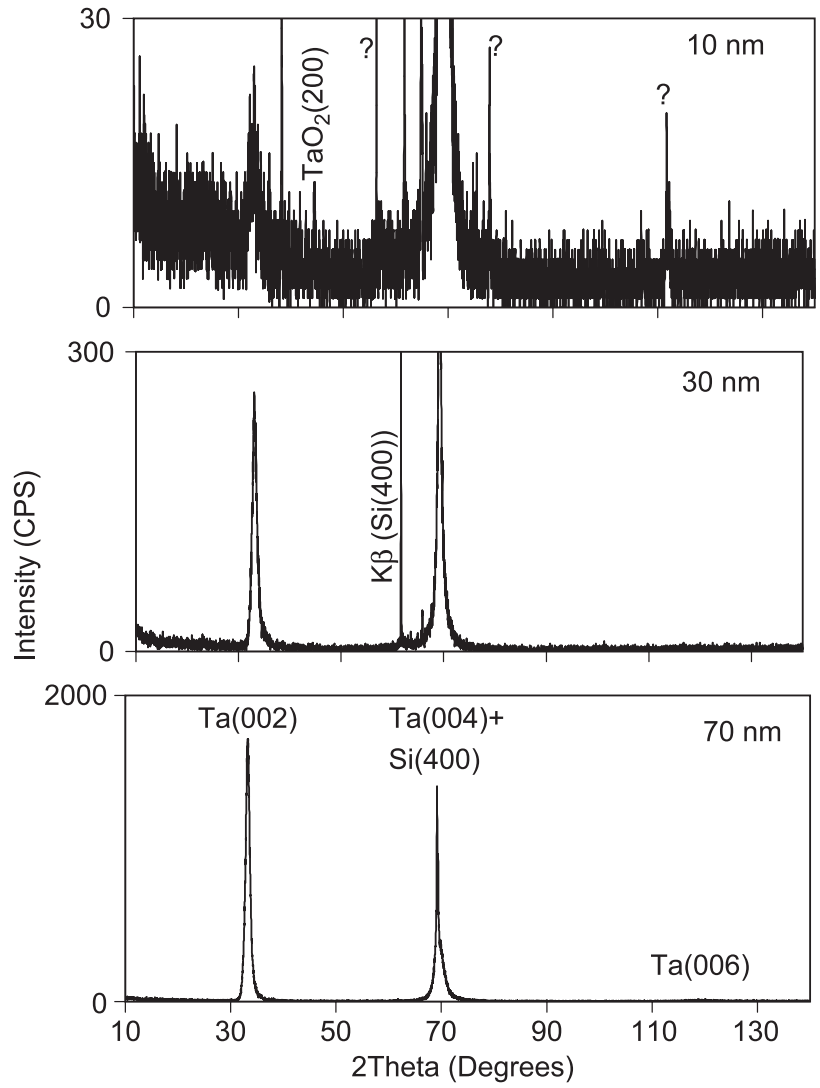

Fig. 1. Theta-2Theta XRD patterns for 10,30 and $70 \mathrm{~nm}$ Ta film deposited on $\mathrm{Si}(100)$ substrates with a $500 \mathrm{~nm} \mathrm{SiO} 2$ interlayer. Miller indices for $\mathrm{Ta}$ and $\mathrm{Si}$ diffraction peaks are also shown. Peaks were aligned for maximum Ta (002) signal. K $\beta$ signal from $\mathrm{Si}(400)$ is not visible in the XRD spectra for $70 \mathrm{~nm}$ due to low signal from $\mathrm{Si}(400)$ peak relative to $\mathrm{Ta}(002)$.

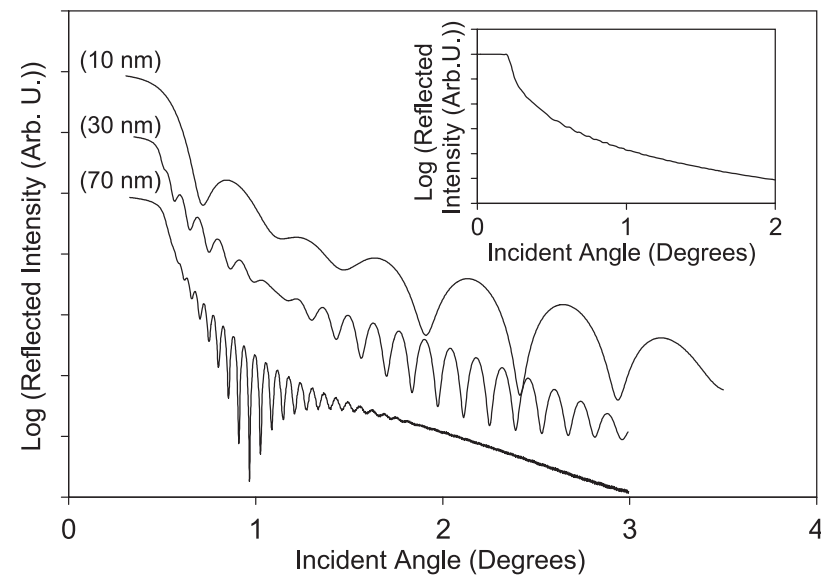

Fig. 2. Experimental XRR curves for 10, 30 and $70 \mathrm{~nm}$ Ta films deposited on $\mathrm{Si}(100)$ substrates with a $500 \mathrm{~nm} \mathrm{SiO}_{2}$ interlayer. The simulated XRR curve for a $500 \mathrm{~nm} \mathrm{SiO}$ layer on $\mathrm{Si}$ substrate is shown in the inset.

identified, several other peaks could not even after a thorough scan of the ICDD database for reasonable Ta compounds. The low signal to the noise ratio could be responsible for phase-identification failure. In our asdeposited films, we did not observe any diffraction peaks for the crystalline phases for tantalum oxide, tantalum silicide $\left(\mathrm{TaSi}_{2}\right)$ or tantalum silicate $\left(\mathrm{TaSiO}_{x}\right)$ phases.

Fig. 2 shows the experimental XRR curves for the asdeposited films. The thickness of $\mathrm{SiO}_{2}$ was independently verified using spectroscopic ellipsometry and was estimated to be $514 \mathrm{~nm}$. At this thickness, the spacing between the Kiessig [14,15] fringes (used for estimating the thickness) in the XRR curves becomes difficult to resolve; thus the thickness determination was not practically possible. The simulated XRR curve for the $500 \mathrm{~nm}$ $\mathrm{SiO}_{2}$ deposited on $\mathrm{Si}$ substrate for $\mathrm{Cu} \mathrm{K}_{\alpha}$ radiation using public domain software is shown as inset in Fig. 2 for the sake of comparison ${ }^{1}$ [16] Consequently, for the simulation of our XRR curves, the thickness of the $\mathrm{SiO}_{2}$ film was initially fixed at values obtained from ellipsometry data and any variations in thickness of this layer were ignored. XRR curves for Ta films could not be simulated without the introduction of a thin interface layer between $\mathrm{Ta}$ and $\mathrm{SiO}_{2}$ layers. The results for the thickness and density of Ta are tabulated in Table 1. The thickness and density of this interface layer was found to be $1.9 \pm 0.2 \mathrm{~nm}$ and $10.5 \pm 0.5 \mathrm{~g} /$ $\mathrm{cm}^{3}$, respectively.

Prior to XPS analysis, the adventitious carbon and the native oxide layer on the surface of metal films were removed by Ar ion sputtering to expose the underlying clean surface. Only Ta metal peaks could be seen in the survey XPS spectra of the films deposited on Si substrate with a $500 \mathrm{~nm} \mathrm{SiO}{ }_{2}$ interlayer. XPS Ar ion sputter depth profile analysis was performed on $10-70 \mathrm{~nm}$ films. Fig. 3 shows the representative depth profile analysis for the 10

\footnotetext{
${ }^{1}$ http://cindy.lbl.gov/optical_constants/layer2.html.
} 
Table 1

Simulated X-ray reflectivity results for oriented $\beta$-Ta films

\begin{tabular}{llcc}
\hline Film & Layer materials & Thickness $[\mathrm{nm}]$ & Density $\left[\mathrm{g} / \mathrm{cm}^{3}\right]$ \\
\hline $10 \mathrm{~nm} \mathrm{Ta}$ & Tantalum & $2.3 \pm 0.1$ & $14.9 \pm 0.3$ \\
& Tantalum & $5.2 \pm 0.1$ & $15.7 \pm 0.3$ \\
& Interface Layer & $1.8 \pm 0.1$ & $10.0 \pm 0.2$ \\
$30 \mathrm{~nm} \mathrm{Ta}$ & Tantalum & $2.1 \pm 0.1$ & $13.6 \pm 0.2$ \\
& Tantalum & $28.0 \pm 0.1$ & $16.0 \pm 0.2$ \\
& Interface Layer & $2.1 \pm 0.1$ & $11.0 \pm 0.1$ \\
$70 \mathrm{~nm} \mathrm{Ta}$ & Tantalum & $2.2 \pm 0.1$ & $5.4 \pm 0.1$ \\
& Tantalum & $32.3 \pm 0.4$ & $16.4 \pm 0.2$ \\
& Tantalum & $36.0 \pm 0.4$ & $15.3 \pm 0.2$ \\
& Interface Layer & $1.8 \pm 0.1$ & $10.5 \pm 0.1$ \\
\hline
\end{tabular}

$\mathrm{nm}$ Ta film deposited on the Si substrate with a $500 \mathrm{~nm}$ $\mathrm{SiO}_{2}$ interlayer. The presence of oxygen during the start of the sputter profile curves was attributed to the presence of the native oxide layer present at the surface of the tantalum metal film. The appearance of silicon and oxygen peaks after about 4 min of sputtering were attributed to the $\mathrm{SiO}_{2}$ interlayer. In order to investigate the chemical composition of the interface, detailed analysis of $\mathrm{Ta} 4 \mathrm{f}, \mathrm{Si}$ $2 \mathrm{p}$ and $\mathrm{O} 1 \mathrm{~s}$ spectra after $3-5 \mathrm{~min}$ of sputtering was carried out.

The Ta $4 \mathrm{f}$ peak fitted spectra after 4.0 min of sputtering showed the presence of metallic Ta $4 \mathrm{f}_{5 / 2}$ and $4 \mathrm{f}_{7 / 2}$ peaks; $1.91 \mathrm{eV}$ separates the $\mathrm{Ta}_{4} 4 \mathrm{f}_{5 / 2}$ and $\mathrm{Ta}_{4 / 2}$ in energy while the peak area ratio of $3: 4$ is expected [17]. These constraints were used in the peak profile modeling. In the absence of the $\mathrm{C} 1 \mathrm{~s}$ peak in our spectra, the binding energies of all the elements were normalized against the binding energy of the metallic Ta $4 \mathrm{f}_{7 / 2}$ peak that was fixed at $21.64 \mathrm{eV}[18,19]$. The fitted Ta $4 \mathrm{f}$ XPS spectra after 5 min of sputtering (Fig. 5) indicated the presence of additional peaks centered at $26.7 \mathrm{eV}\left(\mathrm{Ta} 4 \mathrm{f}_{7 / 2}\right)$ and 28.5 $\mathrm{eV}\left(\mathrm{Ta} 4 \mathrm{f}_{5 / 2}\right)$. These peaks could be attributed to the oxide phase of tantalum [19] and were treated with the assumed area ratio of $3: 4$ as before.

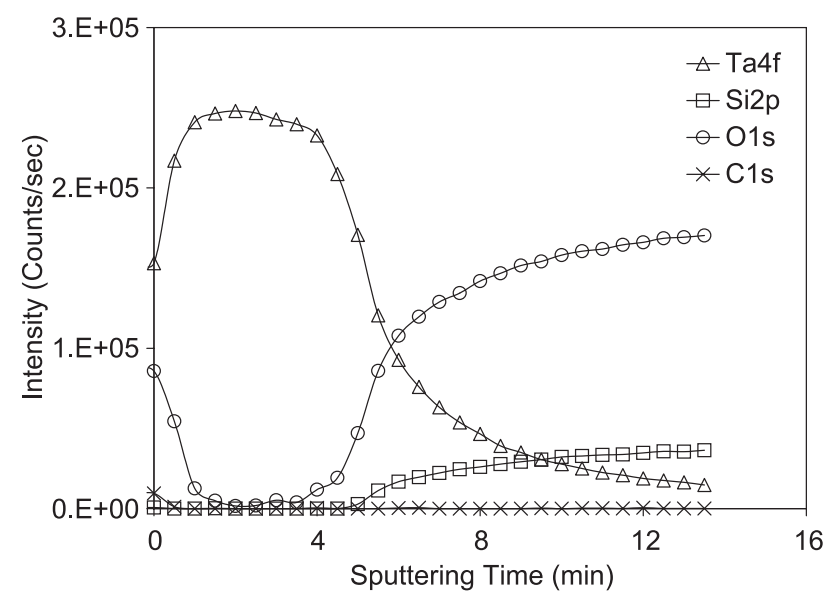

Fig. 3. XPS sputter profile analysis for a $10 \mathrm{~nm}$ Ta metal film on a $\mathrm{Si}(100)$ substrate with a $500 \mathrm{~nm} \mathrm{~S}{ }_{2}$ interlayer. The elemental compositions are indicated $(\Delta)$ Ta 4f, ( $\square)$ Si 2p, (O) O 1s and $(\times)$ C 1s.

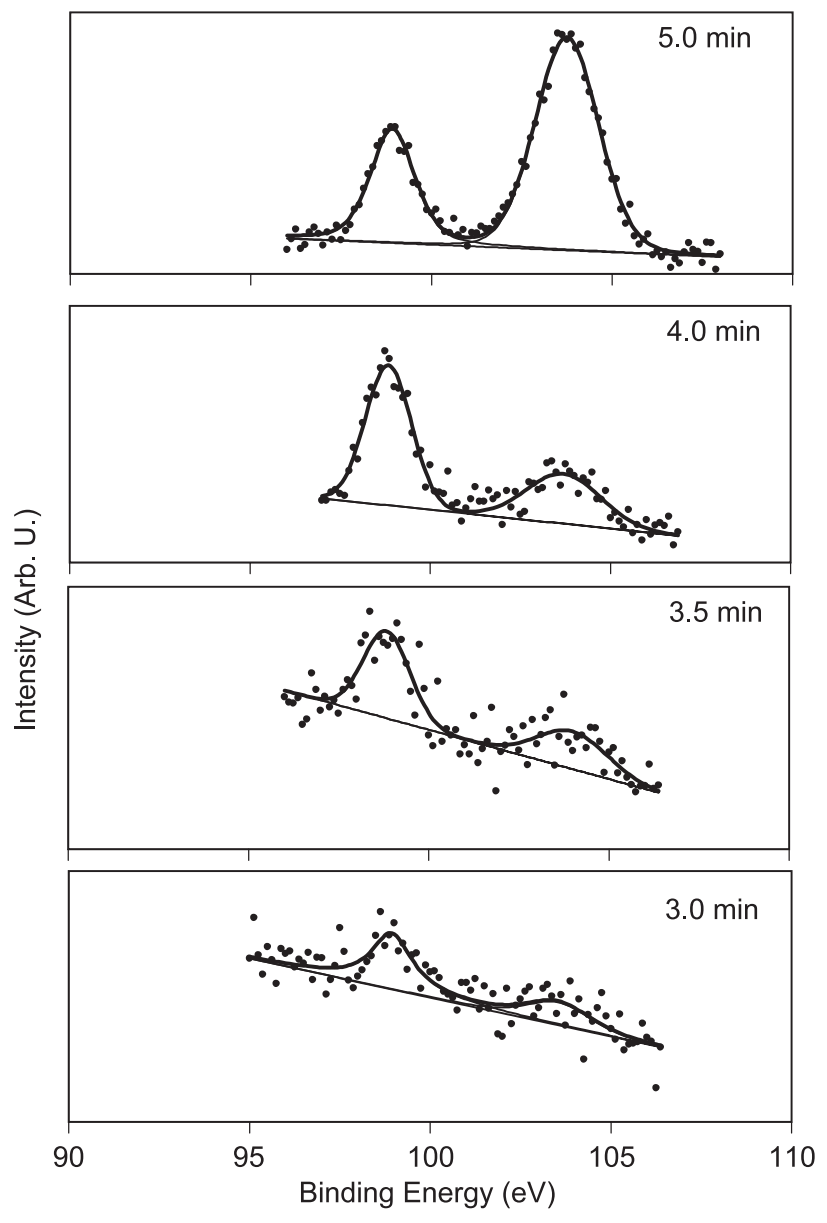

Fig. 4. Experimental and fitted high-resolution Si 2p XPS spectra after the Ta metal film was sputtered for 3-5 min using Ar ions. Dotted points (@) are experimental while the heavy solid curve (-) represents the fitted results. The individual peaks are shown as solid curves (-). A Shirley background used is also shown.

The high-resolution fitted spectra for $\mathrm{Si} 2 \mathrm{p}$ peaks are shown in Fig. 4. As seen in the figure, the $\mathrm{Si} 2 \mathrm{p}$ peaks centered on a binding energy of $98.4 \pm 0.2$ and $103.4 \pm 0.2 \mathrm{eV}$ could be seen in all the spectra. The average peak separation between the two peaks remained constant over this sputtering interval (3-5 min) and was found to be $5.0 \pm 0.2 \mathrm{eV}$. Finally, $\mathrm{O} 1 \mathrm{~s}$ spectra exhibited the presence of peaks centered on $530.5 \pm 0.1$ and $531.8 \pm 0.3 \mathrm{eV}$. The average peak separation between the two peaks was found to be $1.3 \pm 0.3 \mathrm{eV}$. Peak positions for different elemental species after 3-5 min of sputtering interval are shown in Table 2.

\section{Discussion}

Oriented $\beta$-Ta films were deposited on $\mathrm{Si}(100)$ substrates over a $500 \mathrm{~nm} \mathrm{SiO}{ }_{2}$ interlayer. Formation of tetragonal $\mathrm{TaO}_{2}$ oriented along (200) in the $10 \mathrm{~nm}$ Ta film was possibly due to the surface oxidized oriented $\beta$-Ta. The thicknesses of the Ta films were estimated by XRR. While the density of the $70 \mathrm{~nm}$ Ta film was similar to the bulk density of Ta metal 
Table 2

Peak profile parameters for $10 \mathrm{~nm} \beta$-Ta films after different sputtering intervals

\begin{tabular}{|c|c|c|c|c|c|c|}
\hline $\begin{array}{l}\text { Sputter } \\
\text { time } \\
(\mathrm{min})\end{array}$ & Peak & $\begin{array}{l}\text { Peak } \\
\text { position } \\
(\mathrm{eV})\end{array}$ & $\begin{array}{l}\text { Peak } \\
\text { separation } \\
(\mathrm{eV})\end{array}$ & $\begin{array}{l}\text { Band } \\
\text { FWHM }^{\mathrm{a}} \\
(\mathrm{eV})\end{array}$ & $\begin{array}{l}\text { FWHM }^{\mathrm{b}} \\
(\mathrm{eV})\end{array}$ & $\%$ Area \\
\hline \multirow[t]{6}{*}{3.0} & \multirow[t]{2}{*}{$\mathrm{Ta} 4 \mathrm{f}$} & 21.6 & 0.0 & 1.3 & 1.1 & 57.1 \\
\hline & & 23.5 & 1.9 & 1.4 & 1.1 & 42.9 \\
\hline & \multirow[t]{2}{*}{ Si $2 p$} & 98.6 & 0.0 & 1.8 & 1.8 & 46.3 \\
\hline & & 103.3 & 4.7 & 3.4 & 3.4 & 53.7 \\
\hline & \multirow[t]{2}{*}{$\mathrm{O} 1 \mathrm{~s}$} & 530.7 & 0.0 & 1.6 & 1.6 & 56.1 \\
\hline & & 531.8 & 1.2 & 2.7 & 2.7 & 43.9 \\
\hline \multirow[t]{6}{*}{3.5} & \multirow[t]{2}{*}{ Ta $4 \mathrm{f}$} & 21.6 & 0.0 & 1.4 & 1.1 & 57.1 \\
\hline & & 23.6 & 1.9 & 1.4 & 1.1 & 42.9 \\
\hline & \multirow[t]{2}{*}{ Si $2 p$} & 98.4 & 0.0 & 1.4 & 1.4 & 72.8 \\
\hline & & 103.5 & 5.1 & 1.5 & 1.5 & 27.2 \\
\hline & \multirow[t]{2}{*}{$\mathrm{O} 1 \mathrm{~s}$} & 530.6 & 0.0 & 1.2 & 1.2 & 18.8 \\
\hline & & 531.6 & 1.0 & 3.4 & 3.4 & 81.2 \\
\hline \multirow[t]{6}{*}{4.0} & \multirow[t]{2}{*}{ Ta $4 \mathrm{f}$} & 21.6 & 0.0 & 1.4 & 1.1 & 57.1 \\
\hline & & 23.6 & 1.9 & 1.4 & 1.1 & 42.9 \\
\hline & \multirow[t]{2}{*}{ Si $2 p$} & 98.3 & 0.0 & 1.4 & 1.4 & 70.1 \\
\hline & & 103.2 & 4.9 & 1.8 & 1.8 & 29.9 \\
\hline & \multirow[t]{2}{*}{$\mathrm{O} 1 \mathrm{~s}$} & 530.4 & 0.0 & 1.2 & 1.2 & 22.0 \\
\hline & & 531.7 & 1.3 & 3.0 & 3.0 & 78.0 \\
\hline \multirow[t]{8}{*}{5.0} & \multirow[t]{4}{*}{ Ta $4 \mathrm{f}$} & 21.6 & 0.0 & 1.6 & 1.2 & 54.1 \\
\hline & & 23.5 & 1.9 & 1.7 & 1.2 & 40.6 \\
\hline & & 26.7 & 5.0 & 1.6 & 0.9 & 3.0 \\
\hline & & 28.5 & 6.9 & 1.6 & 1.3 & 2.3 \\
\hline & \multirow[t]{2}{*}{ Si $2 p$} & 98.3 & 0.0 & 1.7 & 1.7 & 28.8 \\
\hline & & 103.7 & 4.8 & 2.1 & 2.1 & 71.2 \\
\hline & \multirow[t]{2}{*}{ O 1s } & 530.5 & 0.0 & 1.7 & 1.7 & 22.4 \\
\hline & & 532.2 & 1.7 & 2.2 & 2.2 & 77.6 \\
\hline
\end{tabular}

a Band FWHM - width of the band at one half its height, in electronvolts.

${ }^{\mathrm{b}}$ FWHM - width of the peak component at one half its height, in electronvolts.

$\left(16.7 \mathrm{~g} / \mathrm{cm}^{3}\right)$, the density values for 10 and $30 \mathrm{~nm}$ were lower than those reported in literature. This could be due to the increased presence of voids in the 10 and $30 \mathrm{~nm}$ films. The presence of a low-density top layer in the simulated film structure could be attributed to the presence of native oxides and surface roughness. However, the low-density layer below the Ta metal film was attributed to the interface layer between the $\mathrm{Ta}$ metal and $\mathrm{SiO}_{2}$ layer. The density of the surface layer for the $70 \mathrm{~nm}$ Ta film was considerably lower than those for 10 and $30 \mathrm{~nm}$ films. This was possibly due to the increased surface roughness associated with the $70 \mathrm{~nm}$ film. Assuming additional Ta metal films with similar densities fit the experimental reflectivity curves better. We considered this to be indicative of graded Ta film.

High-resolution XPS depth profile analysis for $10 \mathrm{~nm}$ Ta films (Table 2) shows the presence of Si $2 p$ peaks centered on $98.4 \pm 0.2 \mathrm{eV}$ and $103.4 \pm 0.2 \mathrm{eV}$ and $\mathrm{O} 1 \mathrm{~s}$ peaks centered on $530.5 \pm 0.1$ and $531.8 \pm 0.3 \mathrm{eV}$. The oxide phase of tantalum could only be observed in sample sputtered for 5 min. The accepted binding energy value for elemental $\mathrm{Si}$ $2 \mathrm{p}_{3 / 2}$ is $99.79 \mathrm{eV} \mathrm{[20]} \mathrm{and} \mathrm{that} \mathrm{for} \mathrm{fully} \mathrm{oxidized} \mathrm{SiO}_{2}\left(\mathrm{Si}^{4+}\right)$ is $\sim 103.5 \mathrm{eV}$. It has been reported recently that in case of the formation of tantalum silicide $\left(\mathrm{TaSi}_{2}\right)$ the $\mathrm{Si} 2 \mathrm{p}$ peaks were shifted towards lower energies as compared to bulk elemental silicon and the Ta $4 \mathrm{f}$ peak was shifted towards higher binding energy by $0.5 \mathrm{eV}$ as compared to the metallic tantalum [21]. We did not observe any Ta $4 \mathrm{f}$ peaks for $\mathrm{TaSi}_{2}$ shifted towards higher energies. The absence of this shifted $\mathrm{Ta}$ 4f peak could possibly be due to an overwhelming contribution by metallic Ta $4 \mathrm{f}$ peak to the signal. Therefore, it seems that the $\mathrm{TaSi}_{2}$ phase was formed at the $\beta-\mathrm{Ta} / \mathrm{SiO}_{2}$ interface, as evidenced by the presence of $\mathrm{Si} 2 p$ peaks shifted towards lower energies as compared to bulk elemental silicon.

The peak at $103.4 \mathrm{eV}$ was attributed to the $\mathrm{SiO}_{2}$ layer under the tantalum film. The presence of higher binding $\mathrm{O}$ 1s peak around $531.8 \mathrm{eV}$ is likely due to $\mathrm{SiO}_{2}$. The peak seen at lower binding energy of $530.5 \mathrm{eV}$ is usually associated with tantalum oxide [19] and tantalum silicate [22]. The formation of $\mathrm{TaSiO}_{x}$ is usually indicated by the presence of $\mathrm{Si} 2 \mathrm{p}$ peak at $102.1 \mathrm{eV}, \mathrm{Ta} 4 \mathrm{f}_{7 / 2}$ at $26.2 \mathrm{eV}$ [22] (see also Refs. [1,6,17, 18] in Ref. [22]). The peaks for tantalum oxide could only be seen in films sputtered for 5 $\min$. The chemical states associated with this lower binding energy $\mathrm{O} 1 \mathrm{~s}$ peak are not clear at this stage. XPS results for 30 and $70 \mathrm{~nm}$ Ta film were similar to the results for $10 \mathrm{~nm}$ Ta film.

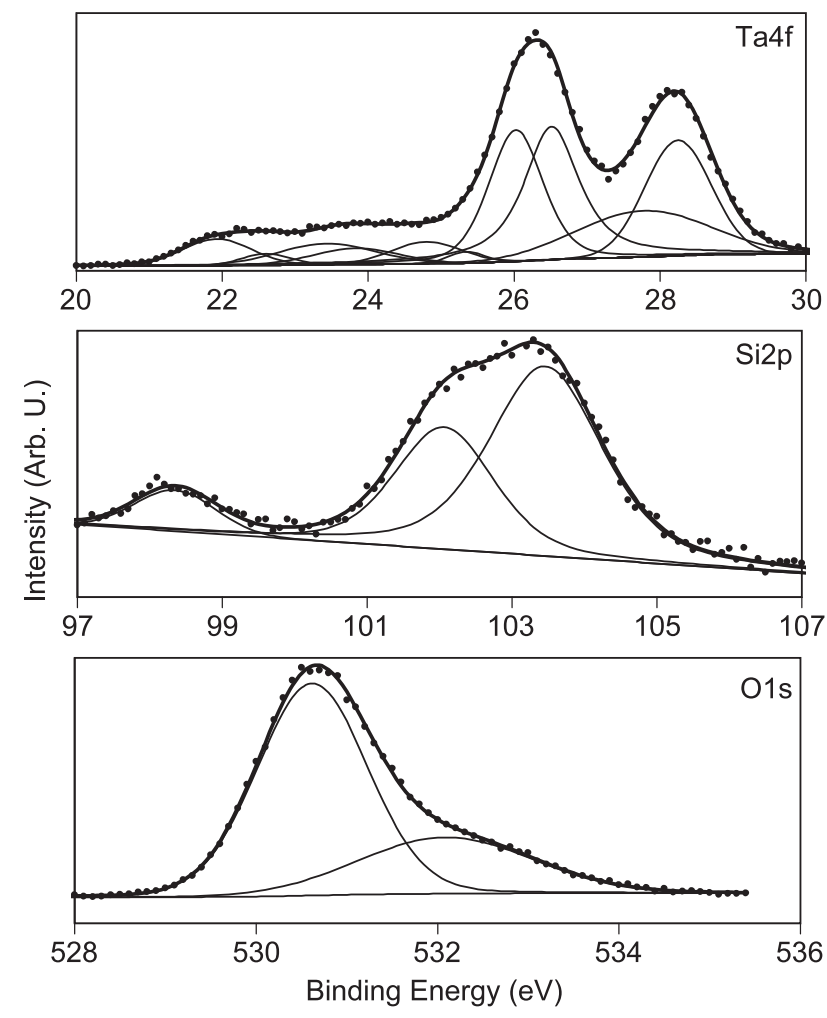

Fig. 5. Experimental and fitted high-resolution Ta 4f, Si 2p, and O 1s XPS

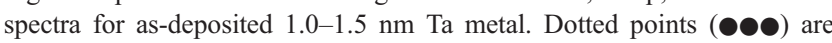
experimental while the heavy solid curve (-) represents the fitted results. The individual peaks are shown as solid curves (-). A Shirley background used is also shown. 
Table 3

Chemical state identification of $1.0-1.5 \mathrm{~nm}$ Ta films on Si substrate with a $500 \mathrm{~nm}$ interlayer

\begin{tabular}{|c|c|c|c|c|c|}
\hline XPS peak & $\begin{array}{l}\text { Binding } \\
\text { energy } \\
(\mathrm{eV})\end{array}$ & $\%$ Area & $\begin{array}{l}\text { FWHM } \\
(\mathrm{eV})\end{array}$ & $\begin{array}{l}\text { Chemical } \\
\text { state }\end{array}$ & \\
\hline \multirow[t]{2}{*}{$\mathrm{O} 1 \mathrm{~s}$} & 530.6 & 71.2 & 1.4 & $\begin{array}{l}\mathrm{TaO}_{x}[19] ; \\
\mathrm{Ta}_{2} \mathrm{O}_{5} ;[19] \\
\mathrm{TaSiO}_{x}[22]\end{array}$ & \\
\hline & 532.1 & 28.8 & 2.3 & $\mathrm{SiO}_{2}[19]$ & \\
\hline \multirow[t]{3}{*}{ Si $2 p$} & 102.1 & 32.5 & 1.6 & $\mathrm{TaSiO}_{x}[22]$ & \\
\hline & 103.5 & 59.9 & 1.8 & $\mathrm{SiO}_{2}[19]$ & \\
\hline & 98.3 & 7.6 & 1.3 & $\mathrm{TaSi}_{2}[21]$ & \\
\hline \multirow[t]{10}{*}{$\mathrm{Ta} 4 \mathrm{f}$} & 21.9 & 4.6 & 1.1 & Ta metal $[18,19]$ & $4 f_{7 / 2}$ \\
\hline & 23.8 & 3.4 & 1.4 & & $4 f_{5 / 2}$ \\
\hline & 22.6 & 1.4 & 0.8 & $\mathrm{TaSi}_{2}[21]$ & $4 f_{7 / 2}$ \\
\hline & 25.3 & 1.0 & 0.6 & & $4 f_{5 / 2}$ \\
\hline & 23.4 & 5.1 & 1.6 & Possibly $\mathrm{TaO}_{x}$ & $4 f_{7 / 2}$ \\
\hline & 24.8 & 3.8 & 1.1 & & $4 f_{5 / 2}$ \\
\hline & 26 & 20.5 & 0.9 & $\mathrm{TaO}_{x} ; \mathrm{TaSiO}_{6}[22]$ & $4 f_{7 / 2}$ \\
\hline & 27.8 & 15.4 & 2.2 & & $4 f_{5 / 2}$ \\
\hline & 26.5 & 25.6 & 0.9 & $\mathrm{Ta}_{2} \mathrm{O}_{5}[19]$ & $4 f_{7 / 2}$ \\
\hline & 28.2 & 19.2 & 1.1 & & $4 f_{5 / 2}$ \\
\hline
\end{tabular}

Despite the results indicating the presence of $\mathrm{TaSi}_{2}$ at the interface, it must be noted that $\mathrm{TaSi}_{2}$ could also be formed during the XPS depth profiling using Ar ions [23]. Also, our XPS depth profile analysis also did not indicate the formation of $\mathrm{TaSiO}_{x}$ that is typically confirmed by the presence of a Si $2 \mathrm{p}$ peak at $102.1 \mathrm{eV}$, a Ta $4 \mathrm{f}$ at $26.2 \mathrm{eV}$ and a $\mathrm{O} 1 \mathrm{~s}$ peak at $530.6 \mathrm{eV}$ [22]. Preferential sputtering in films with heavy metals is a common problem; hence, it is quite possible that the $\mathrm{TaSiO}_{x}$ phase was reduced during sputter depth profiling. In order to conclusively establish silicide and silicate formation at the interface, it was necessary to probe the film interface without using $\mathrm{Ar}$ ion sputter process.

Because XPS is a surface sensitive technique, the XPS signals originate from the top few nanometers of sample. The inelastic mean free path (IMFP) has been defined as the average of the distances, measured along the trajectories, that particles with a given energy travel between inelastic collisions in a substance [24,25]. The estimated value of IMFP for Ta metal, at energies corresponding to $\mathrm{Al} \mathrm{K} \alpha \mathrm{X}$ rays is $1.88 \mathrm{~nm}$ [26]. Hence, in order to evaluate the interface without sputter depth profile analysis, Ta metal films with thickness of the order of $1.0-1.5 \mathrm{~nm}$ were deposited under conditions similar to our $10-70 \mathrm{~nm} \mathrm{Ta}$ metal films.

The presence of the Si $2 p$ peak in the survey XPS spectra for the $1.0-1.5 \mathrm{~nm}$ Ta metal film clearly established the fact that we were able to look into the interface below the tantalum metal film without sputtering the metal surface. $\mathrm{Si}$ 2p, Ta $4 \mathrm{f}$ and $\mathrm{O}$ 1s high-resolution XPS spectra are shown in Fig. 5. The binding energies of all the elements were normalized against the binding energy of $\mathrm{C} 1 \mathrm{~s}$ peak that was fixed at $284.8 \mathrm{eV}$. Si 2 p spectra showed the presence of peaks at $98.3 \mathrm{eV}, 102.0 \mathrm{eV}$ and $103.5 \mathrm{eV}$. The fitted $\mathrm{O} 1 \mathrm{~s}$ spectra showed the presence of peaks at $530.6 \mathrm{eV}$ and 532.1 $\mathrm{eV}$. The fitted Ta $4 \mathrm{f}$ spectra showed the presence of metallic and oxidized tantalum films, along with a contribution from silicide and silicate phases. Since the oxidized tantalum was likely due to the presence of native oxide layer present on the surface of the metallic tantalum, the concentration of oxidized tantalum in the $\mathrm{Ta} 4 \mathrm{f}$ spectra was relatively high. The Ta $4 \mathrm{f}_{7 / 2}$ peak positions for tantalum metal and $\mathrm{Ta}_{2} \mathrm{O}_{5}$ reported in NIST database are $21.7 \pm 0.2$ and $26.5 \pm 0.5 \mathrm{eV}$, respectively, while $\mathrm{O}$ 1s binding energy for $\mathrm{Ta}_{2} \mathrm{O}_{5}$ is $530.3 \pm 0.5 \mathrm{eV}$ [19]. The fitted peak parameters and their possible chemical states are presented in Table 3. A detailed comparison of our data with those reported in literature $[19,21,22]$ established that the as-formed $\beta-\mathrm{Ta} / \mathrm{SiO}_{2}$ interface was comprised of tantalum silicate and silicide phases. This interface was reduced during sputter depth profile analysis using Ar ions, as a result of which the tantalum silicate phase could not be observed during the sputter depth profile XPS analysis.

\section{Conclusions}

Ion-beam sputter deposited $10-70 \mathrm{~nm} \beta$-Ta metal films oriented along (001) were deposited on Si (100) substrate with a $500 \mathrm{~nm} \mathrm{SiO}_{2}$ interlayer. Simulated XRR curves indicate the presence of a $1.9 \pm 0.2 \mathrm{~nm}$ interface layer with a density of $10.5 \pm 0.5 \mathrm{~g} / \mathrm{cm}^{3}$, lying between the graded tantalum metal and $\mathrm{SiO}_{2}$ interlayer. XPS investigations indicate that the interface was composed of $\mathrm{TaSi}_{2}, \mathrm{TaSiO}_{x}$, $\mathrm{SiO}_{2}$ and $\mathrm{Ta}_{2} \mathrm{O}_{5}$. Moreover, the $\mathrm{TaSiO}_{x}$ layer was reduced during sputter depth profile analysis using $\mathrm{Ar}$ ions.

\section{Acknowledgements}

The authors would like to acknowledge the financial support provided by the NSF instrument Grant Nos. NSFCHE-9808024 and NSF-DMR-0076180. This work was also supported in part by the NSF Engineering Research Centers Program under grant EEC-0310717.

\section{References}

[1] S.P. Murarka, S.W. Hymes, Crit. Rev. Solid State 20 (1995) 87.

[2] C. Ryu, K.W. Kwon, A.L.S. Loke, H. Lee, T. Nogami, V.M. Dubin, R.A. Kavari, G.W. Ray, S.S. Wong, IEEE Trans. Electron Devices 46 (1999) 1113.

[3] K.V. Kwon, C. Ryu, R. Sinclair, S.S. Wong, Appl. Phys. Lett. 71 (1997) 3069.

[4] S.L. Lee, D. Windover, T.M. Lu, M. Audino, Thin Solid Films 420 (2002) 287

[5] J.H. Wang, L.J. Chen, Z.C. Lu, C.S. Hsiung, W.Y. Hsieh, T.R. Yew, J. Vac. Sci. Technol., B 20 (2002) 1522.

[6] L. Gladczuk, C. Joshi, A. Pater, J. Guiheen, Z. Iqbal, M. Sosnowski, Materials Research Society Symposia Proccedings, 2003, p. FF7.2.1. 
[7] P.N. Baker, Thin Solid Films 14 (1972) 3.

[8] A.Q. Jiang, A. Yohannan, N.O. Nnolim, T.A. Tyson, L. Axe, S.L. Lee, P. Cote, Thin Solid Films 437 (2003) 116.

[9] C. Montcalm, S.M. Lee, D. Burtner, A. Dummer, D. Siegfried, I. Wagner, M. Watanabe, Annual Technical Conference ProceedingsSociety of Vacuum Coaters, 2002, p. 245.

[10] S. Kohli, J.A. Theil, R.D. Snyder, C.D. Rithner, P.K. Dorhout, J. Vac. Sci. Technol., B 21 (2003) 719.

[11] S. Kohli, C.D. Rithner, P.K. Dorhout, J. Appl. Phys. 91 (2002) 1149.

[12] Powder Diffraction File, Joint Committee on Powder Diffraction Standards - International Centre for Diffraction Data, Newton Square, PA., Card No. 25-1280.

[13] Powder Diffraction File, Joint Committee on Powder Diffraction Standards - International Centre for Diffraction Data, Newton Square, PA., Card No. 43-1046.

[14] H. Kiessig, Ann. Phys. 10 (5) (1931) 769.

[15] V.P. Holy, U. Pietsch, T. Baumbach, High-Resolution X-ray Scattering from Thin Films and Multilayers, Springer-Verlag, Berlin, 1999.

[16] B.L. Henke, E.M. Gullikson, J.C. Davis, At. Data Nucl. Data Tables 54 (1993) 181.

[17] D. Briggs, M.P. Seah (Eds.), Practical Surface Analysis: Auger and X-Ray Photoelectron Spectroscopy, John Wiley and Sons, 1996.
[18] J.F. Vanderveen, F.J. Himpsel, D.E. Eastman, Phys. Rev., B 25 (1982) 7388.

[19] C.D. Wagner, A.V. Naumkin, A. Kraut-Vass, J.W. Allison, C.J. Powell, J.R. Rumble Jr., NIST Standard Reference Database 20, Version 3.4 (Web Version), National Institute of Standards and Technology, Gaithersburg, MD, 2000.

[20] B.V. Crist, Handbook of Monochromatic XPS Spectra Semiconductors, John Wiley and Sons, West Sussex, UK, 2000, p. 356.

[21] M. Zier, S. Oswald, R. Reiche, K. Wetzig, Anal. Bioanal. Chem. 375 (2003) 902.

[22] X. Zhao, N.P. Magtoto, M. Leavy, J.A. Kelber, Thin Solid Films 415 (2002) 308.

[23] B.R. Chakraborty, S. Hofmann, Thin Solid Films 204 (1991) 163.

[24] C.J. Powell, A. Jablonski, I.S. Tilinin, S. Tanuma, D.R. Penn, J. Electron. Spectrosc. 99 (1999) 1.

[25] J.F. Moulder, W.F. Stickle, P.E. Sobol, K.D. Bomben, W.F. Stickle, P.E. Sobol, K.D. Bomben, Handbook of X-ray Photoelectron Spectroscopy-A Reference Book of Standard Spectra for Identification and Interpretation of XPS Data, Physical Electronics, Eden Prairie, MN, 1995.

[26] C.J. Powell, A. Jablonski, NIST Electron Inelastic-Mean-Free-Path Database-Version 1.1, National Institute of Standards and Technology, Gaithesburg, MD, 2000. 